\title{
ПРОДВИЖЕНИЕ ГЛОБАЛЬНОГО И РЕГИОНАЛЬНОГО МЕЖДУНАРОДНОГО ПРАВОВОГО РЕГУЛИРОВАНИЯ В ОБЛАСТИ ПРЕДУПРЕЖДЕНИЯ И ЛИКВИДАЦИИ ЧРЕЗВЫЧАЙНЫХ СИТУАЦИЙ, ПРИРОДНЫХ И ТЕХНОГЕННЫХ КАТАСТРОФ
}

Аннотация. В статье рассмотрены вопросы международного сотрудничества Российской Федерачии в сфере предупреждения и ликвидации чрезвычайных ситуаций природного и техногенного характера и проведения аварийно-спасательных работ. Проанализированы международные договоры Российской Федерации в рассматриваемой области, заключенные как на многостороннем, так и двустороннем уровнях. В иелях совершенствования международно-правового регулирования в указанной области, а также заполнения отдельных международно-правовых лакун авторами подготовлены два проекта международных договоров универсального и регионального характера, а именно: проект Конвенции Организации Объединенных Наций по предупреждению и ликвидачии последствий техногенных и природных катастроф, а также проект Договора о согласованных подходах государств-членов Евразийского экономического союза к предупреждению и ликвидации чрезвычайных ситуаций природного и техногенного характера и проведению аварийно-спасательных работ. Методологию исследования составляют общенаучные способы познания $и$ специальные юридические методы: формально-юридический; сравнительно-правовой; анализ; синтез; логический метод; метод юридического моделирования и прогнозирования. Проект Конвенции Организации Объединенных Наций по предупреждению и ликвидации последствий техногенных и природных катастроф призван восполнить пробел на уровне универсального международно-правового регулирования под эгидой Организации Объединенных Наций, поскольку вопросы, регламентируемые в проекте Конвениии ООН, до сих пор не нашли отражения в международном договоре универсального характера, т.е. в таком международном правовом акте, в котором участвует подавляющее большинство государств мира. Также разработан проект Договора о согласованных подходах государств-членов Евразийского экономического союза к предупреждению и ликвидации чрезвычайных ситуаций природного и техногенного характера и проведению аварийно-спасательных работ.

Ключевые слова: Чрезвычайные ситуаичи, катастрофы, стихийные бедствия, аварийно-спасательные работы, компетентные органы, безопасность, вызовы, Российская Федерация, Организация Объединенных Наџий, Евразийский экономический союз.

Abstract: This article examines the questions of international participation of the Russian Federation in the area of prevention and liquidation of emergency situations of natural and technogenic character, as well as carrying out of emergency rescue missions. Analysis is conducted on both, multilateral and bilateral international agreements of the Russian Federation in this sphere. In order to improve the international legal regulation 
in this field, as well as to fill-in the separate lacunas of international law, the authors prepared two drafts of international law of both, universal and regional character; more precisely: Draft UN Convention on Prevention and Liquidation of the Aftermath of Technogenic and Natural Catastrophes, as well as the Draft Treaty on Coordinated Approaches of the Member-States of Eurasian Economic Union towards Prevention and Liquidation of Emergency Situations of Natural and Technogenic Character and Carrying Out Emergency Rescue Missions. The Draft UN Convention on Prevention and Liquidation of the Aftermath of Technogenic and Natural Catastrophes is called to fill-in the gap on the level of universal international law regulation under the aegis of the United Nations, since the issues regulated in the UN Convention draft has yet to find the reflection in the international treaty of a universal character; in other words, in an international legal act that is represented by the vast majority of the world's countries.

Keywords: Russian Federation, challenges, security, competent authorities, rescue operations, natural disasters, catastrophes, emergency situations, United Nations, Eurasian Economic Union.

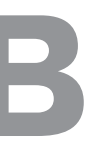

современном мире международные договоры являются одним из самых эффективных регуляторов международных отношений, им принадлежит особая роль в укреплении международного правопорядка, что в настоящее время в эпоху повышенной международной турбулентности не снижает значимости в необходимости модернизации действующего международно-правового регулирования, а также в разработке и принятии новых международных договоров. Международные договоры являются правовой основой регулирования отношений субъектов международного права. Они - существенный элемент стабильности международного правопорядка и функционирования правового государства. В современный период международные договоры стали важнейшей составной частью реализации внешней политики Российского государства [1]. Такая деятельность является также эффективным инструментом внешней политики Российской Федерации, позволяющим влиять на политические, экономические и другие процессы за рубежом, отстаивая гуманитарными методами интересы России, содействовать формированию союзнических интересов, обеспечивая создание так называемого «пояса добрососедства» по периметру российских границ, интегрироваться в мировые гуманитарные и торгово-экономические процессы, а также рассчитывать на действенную ответную помощь[2].

Как особый процесс, процесс разработки, принятия и введения в действие международных договоров - очень трудоемкая, сложная и специфическая деятельность. Во-многом она зависит от целого набора политических, экономических и иных факторов, имеющих место как в отдельных государствах, регионах, так и в мире в целом. В то же время, согласовывая свои интересы и закрепляя результат такого согласования в нормах международного права, основным источником которых в настоящее время является международный договор, государства могут решать определенные задачи и достигать необходимых целей. При этом международный договор выступает наиболее подходящей формой для решения сложных задач, выходящих за рамки одного государства и имеющих трансграничный характер, т.к. в такого рода международно-правовом акте, при наличии соответствующих воль и интересов, государства могут достаточно де- 
тально установить те правила, которыми они будут руководствоваться при решении определенных проблем. Очевидно, что вопросы сотрудничества государств в области предупреждения и ликвидации чрезвычайных ситуаций природного и техногенного характера и проведения аварийно-спасательных работ выходят далеко за рамки национальных границ. Это предопределяет необходимость дальнейшего совершенствования международно-правовой базы, имеющейся в данной сфере.

Основополагающими принципами в деле защиты лиц в случае бедствий являются солидарность и сотрудничество, причем как между государствами, так и индивидами. Однако сотрудничество не должно толковаться как ограничивающее прерогативы суверенного государства в рамках международного права. Напротив, этот принцип подчеркивает уважение суверенитета государства и, как следствие, невмешательства в его дела, а также главную роль государственных властей в деле инициирования, организации, координации и принятии мер по защите лиц в случае бедствий [3].

Как справедливо отмечает Л.А. Большов, «опыт аварий показал, что необходимо развивать систему оперативного международного взаимодействия (международные центры аварийного реагирования) в части оперативного оповещения, взаимопомощи и информирования о развитии аварийных процессов и их последствиях, а также мерах, принимаемых по ликвидации аварийной ситуации. Опыт международного взаимодействия экспертов из различных стран позволяет вырабатывать рекомендации по управлению аварией, защитным мерам и оценке их эффективности» [4].

Роль международных рекомендательных актов является весьма значительной в сотрудничестве государств по различным вопросам, связанным с предупреждением и ликвидацией чрезвычайных ситуаций, природных и техногенных катастроф, а также минимизации их последствий. Однако, по нашему мнению, без международного правового регулирования, имеющего обязательный характер, в решении данных вопросов в условиях угрожающего роста количества аварий и катастроф, - не обойтись.

Нельзя не отметить, что в процессе подготовки и заключения международных договоров важнейшее значение имеет принцип сотрудничества государств, который играет особую роль в обеспечении международной коллективной и национальной безопасности [5].

Сотрудничество государств, вытекающее из заключения и реализации международных договоров в области предупреждения и ликвидации чрезвычайных ситуаций природного и техногенного характера и проведения аварийно-спасательных работ, является необходимым ответом мирового сообщества в целом и каждого отдельного государства на ряд глобальных угроз. При этом роль заключения международных договоров в рассматриваемой области объективно возрастает в последние годы в связи с различными катастрофами и бедствиями, выходящими за рамки одного государства, т.е. имеющими трансграничное негативное воздействие.

Проведение единой межгосударственной согласованной политики в области предупреждения и ликвидации чрезвычайных ситуаций трансграничного характера, - пишет Е.Г. Данилова, - является архиважным направлением, способствующим обеспечению безопасности населения и территорий государств, позволяющим не только сохранить человеческие жизни, но и снизить материальный ущерб каждой из стран [6]. 
Для Российской Федерации правовое обеспечение эффективной реализации международных договоров в области предупреждения и ликвидации чрезвычайных ситуаций природного и техногенного характера и проведения аварийно-спасательных работ играет центральную роль для защиты интересов Российской Федерации и безопасности государства.

Применительно к рассматриваемой сфере наиболее распространенными международными регуляторами являются международные договоры, т.к. эти источники международного права наиболее эффективно могут регламентировать отношения между государствами на различных уровнях. Данный вывод обусловлен следующими обстоятельствами:

- в международном договоре в области предупреждения и ликвидации чрезвычайных ситуаций природного и техногенного характера и проведения аварийно-спасательных работ государства посредством своих органов согласовывают интересы и позиции, которые находят отражение в международно-правовых нормах;

- международные договоры налагают на государства международно-правовые обязательства и должны добросовестно исполняться органами государства, юридическими и физическими лицами;

- в случае невыполнения обязательств по международному договору может возникнуть вопрос о международной ответственности государства как субъекта международного права;

- международные договоры обладают приоритетом по отношению к внутригосударственным нормативным правовым актам, что в Российской Федерации закреплено в конституционной норме ч. 4 ст. 15;

- самоисполнимые положения международных договоров могут непосредственно применяться в рамках российской правовой системы согласно ч. 4 ст. 15 Конституции Российской Федерации, a также п. 3 ст. 5 Федерального закона «О международных договорах Российской Федерации» [7].

С точки зрения уровня международных договоров Российской Федерации в сфере предупреждения и ликвидации чрезвычайных ситуаций и проведения аварийно-спасательных работ следует отметить, что такие международные договоры заключены как на межгосударственном и межправительственном, так и на межведомственном уровнях. Причем на межправительственном уровне заключен основной массив рассматриваемого вида международных договоров.

Согласно теории международного права независимо от того, на каком уровне заключен международный договор, он является договором государства в целом, и именно государство несет ответственность за его реализацию.

В соответствии с данными, размещенными на официальном сайте Министерства Российской Федерации по делам гражданской обороны, чрезвычайным ситуациям и ликвидации последствий стихийных бедствий, в настоящее время действует более 40 международных межправительственных договоров в области предупреждения и ликвидации чрезвычайных ситуаций природного и техногенного характера и проведения аварийно-спасательных работ [8].

На межправительственном уровне международные договоры в области предупреждения и ликвидации чрезвычайных ситуаций природного и техногенного характера и проведения аварийно-спасательных работ заключены с правительствами следующих государств: Болгарии, Швейцарии, Германии, Франции, Италии, Польши, Беларуси, Финляндии, Молдовы, Словакии, 
Норвегии, Венгрии, Швеции, Грузии, Армении, Португалии, Греции, Испании, Казахстана, Монголии, Таджикистана, Киргизии, Узбекистана, Азербайджана, США, Перу, Египта, Южной Осетии, Абхазии, Индии, Латвийской Республики, Китайской Народной Республики, Сербии, Японии, Словении, Украины.

Отдельный блок в системе международно-правового регулирования отношений в области предупреждения и ликвидации чрезвычайных ситуаций природного и техногенного характера и проведения аварийно-спасательных работ занимают международные договоры Российской Федерации межведомственного характера [9].

Анализ содержания международных договоров межведомственного характера в области предупреждения и ликвидации чрезвычайных ситуаций природного и техногенного характера и проведения аварийно-спасательных работ показывает, что они содержат, как правило, нормы конкретного и четкого, а не общего содержания. Данные договоры достаточно детально регламентируют области взаимного сотрудничества министерств и ведомств.

С точки зрения международного права, несмотря на уровень органа, от имени которого заключен международный договор, он является юридически обязательным и должен добросовестно исполняться. Вместе с тем, следует учитывать, что во взаимоотношениях двух государств международные договоры межведомственного характера должны соответствовать межгосударственным и межправительственным международным договорам, что обусловлено уровнем органов, представляющих государство на международной арене.

Относительно классификации международных договоров в области предупреждения и ликвидации чрезвычайных ситуаций природного и техногенного характера и проведения аварийно-спасательных работ мы можем заметить, что указанные международные договоры заключаются на следующих уровнях: универсальном, региональном, двустороннем.

Многосторонние международные договоры в рассматриваемой сфере действуют в рамках СНГ, ШОС, Совета Баренцева/ Евроарктического региона, Организации Черноморского экономического сотрудничества, Международной организации гражданской обороны и т.д.

На уровне многосторонних международных договоров Российской Федерации и иных международно-правовых актов, действующих в рамках международных организаций, регламентируются, в частности, следующие вопросы:

- о взаимодействии при оказании помощи в ликвидации чрезвычайных ситуаций;

- о взаимодействии в области предупреждения и ликвидации последствий чрезвычайных ситуаций природного и техногенного характера;

- о трансграничном воздействии промышленных аварий;

- о международном сотрудничестве по вопросам, связанным с последствиями аварии на Чернобыльской АЭС;

- о сотрудничестве и взаимодействии в области изучения землетрясений и прогнозирования сейсмической опасности;

- о социальной защите и охране здоровья граждан, подвергшихся воздействию радиации в результате Чернобыльской и других радиационных катастроф и аварий, а также ядерных испытаний.

В свою очередь, в рамках двусторонних международных договоров в области предупреждения и ликвидации чрезвычайных ситуаций природного и техногенного характера и проведения аварийно-спасательных работ регламентируются, в частности, следующие вопросы: 
- о сотрудничестве в случае стихийных бедствий и крупных аварий;

- о взаимной помощи при стихийных бедствиях или крупных авариях по вопросам сотрудничества в области изучения последствий радиационных аварий и обмена опытом управления послеаварийными ситуациями;

- в области защиты населения, по вопросам прогнозирования и предупреждения чрезвычайных ситуаций и взаимной помощи в случае стихийных бедствий или аварий;

- о сотрудничестве в области предупреждения промышленных аварий, стихийных бедствий и ликвидации их последствий;

- о сотрудничестве в области гражданской обороны, предупреждения промышленных аварий, стихийных бедствий и ликвидации их последствий;

- о сотрудничестве в области обеспечения готовности к гуманитарным чрезвычайным ситуациям и проведения операций по оказанию помощи;

- о сотрудничестве в области изучения радиационных воздействий с целью минимизации влияния последствий радиоактивного загрязнения на здоровье человека и окружающую среду.

Однако анализ имеющегося международно-правового регулирования в рассматриваемой сфере показывает, что до сих пор оно остается весьма фрагментарным и не покрывает всех проблем, возникающих при трансграничных чрезвычайных ситуациях природного и техногенного характера и проведении аварийно-спасательных работ. При этом очевидно, что нуждается в совершенствовании как универсальная международно-правовая база, принимаемая под эгидой Организации Объединенных Наций, так и международные договоры, создающиеся в рамках региональных межгосударственных объединений и международных организаций.

Организация Объединенных Наций в современных условиях глобальных вызовов и угроз является единственной универсальной международной межправительственной организацией, под эгидой которой (включая специализированные учреждения $\mathrm{OOH}$ ) может концентрироваться самый широкий спектр вопросов и направлений международного сотрудничества, включая предупреждение и ликвидацию последствий техногенных и природных катастроф.

Проект Конвенции Организации Объединенных Наций по предупреждению и ликвидации последствий техногенных и природных катастроф (далее - проект Конвенции ООН) разработан в инициативном порядке группой специалистов-экспертов Института законодательства и сравнительного правоведения при Правительстве Российской Федерации [10] и призван восполнить пробел на уровне универсального международно-правового регулирования под эгидой Организации Объединенных Наций, поскольку вопросы, регламентируемые в проекте Конвенции OОН, до сих пор не нашли отражения в международном договоре универсального характера, т.е. в таком международном правовом акте, в котором участвует подавляющее большинство государств мира.

Несмотря на то, что вопросы сотрудничества в сфере предупреждения и ликвидации последствий природных и техногенных катастроф регламентируются в основном посредством двусторонних международных договоров, а также ряда многосторонних международных договоров, в рамках ООН до настоящего времени не заключена универсальная конвенция, посвященная регулированию межгосударственных отношений в рассматриваемой сфере. 
В числе целей Конвенции следовало бы обозначить, в частности, следующие:

- повышение эффективности реагирования на природные и техногенные катастрофы;

- создание правовых и организационных основ сотрудничества государств-участников Организации Объединенных Наций по предупреждению и ликвидации последствий техногенных и природных катастроф;

- развитие международного сотрудничества в области гражданской обороны в сферах предотвращения, прогнозирования, подготовки, реагирования и посткризисного управления ситуацией в интересах пострадавших и для защиты имущества и окружающей среды.

В проекте Конвенции содержится регулирование, в частности, следующих вопросов:

- принципы сотрудничества государств;

- взаимодействие компетентных органов;

- обмен информацией;

- осуществление сотрудничества в случае возникновения чрезвычайной ситуации природного или техногенного характера;

-права и обязанности принимающего и направляющего государства;

- порядок направления запросов об оказании помощи;

-разработка мер и методов увеличения возможностей в области предупреждения стихийных бедствий, техногенных чрезвычайных ситуаций и ликвидации их последствий.

Кроме того, важно подчеркнуть, что согласно проекту Конвенции государства-участники осуществляют свои обязательства согласно настоящей Конвенции в соответствии с принципами суверенного равенства и территориальной целостности государств, принципом невмешательства во внутренние дела других государств, принципом уважения и защиты прав и свобод человека.

В статье 4 проекта Конвенции ООН устанавливаются также специальные принципы по оказанию помощи государствам, пострадавшим в ходе чрезвычайных или техногенных катастроф на основании международного запроса о помощи: может предоставляться только та помощь, которая была запрошена принимающим государством-участником или которая была предложена помогающим государством и одобрена принимающим государством-участником. Кроме того, в указанной статье особо оговариваются следующие подходы к международному оказанию помощи:

- все предложения по оказанию помощи должны уважать суверенитет, независимость и территориальную целостность принимающего государства, а также принцип невмешательства во внутренние дела этого государства, не нарушая при этом его традиций и обычаев;

- предложение по оказанию помощи не должно рассматриваться как вмешательство во внутренние дела принимающего государства-участника;

- помощь должна предоставляться без каких-либо ограничений, в частности расы, цвета кожи, пола, языка, религии, политических или других убеждений, национального или социального происхождения, благосостояния, места рождения или других обстоятельств;

- помощь должна предоставлять ся в духе гуманности, солидарности и беспристрастности;

- рассмотрение предложений помощи и просьб об ее оказании и принятие решений по ним должны осуществляться в кратчайшие сроки государствами-участниками, которым они адресованы.

Подобный подход полностью согласуется с общепризнанными принципами и 
нормами международного права, включая принципы: защиты прав и свобод человека, суверенного равенства государств, невмешательства во внутренние дела государств, нерушимости государственных границ и сохранения территориальной целостности государств.

Проект Конвенции ООН регламентирует также вопросы по взаимодействию компетентных органов Сторон по оказанию помощи в случае возникновения чрезвычайных ситуаций природного и техногенного характера, обмен информацией, порядок рассмотрения запросов о помощи с учетом соблюдения общепризнанных принципов и норм международного права.

Проект Конвенции ООН предусматривает базовый международно-правовой подход к национальному регулированию вопросов оказания помощи в случаях предупреждения и ликвидации чрезвычайных и техногенных катастроф: каждое государство-участник Конвенции принимает, в соответствии с основополагающими принципами своей правовой системы, необходимые меры, включая законодательные и административные меры, для обеспечения осуществления своих обязательств согласно настоящей Конвенции (статья 23).

В проекте Конвенции ООН включена статья о запрете формулирования оговорок (статья 25), в целях более эффективного осуществления сотрудничества по всем направлениям, предусмотренным Конвенцией без изъятий и ограничений.

Предполагается, что для вступления в силу Конвенции, необходимо 20 ратификационных грамот или документов о принятии, утверждении или присоединении. Такое количество документов о выполнении необходимых внутригосударственных процедур с одной стороны позволит Конвенции вступить в силу в случае ее принятия достаточно оператив- но, а с другой стороны обеспечит участие достаточного количества государств для эффективного осуществления Конвенции.

В то же время, восполняя пробелы в универсальном международно-правовом регулировании в области предупреждения и ликвидации чрезвычайных ситуаций природного и техногенного характера и проведения аварийно-спасательных работ, нельзя забывать и о региональном уровне. С точки зрения обеспечения интересов Российской Федерации, это прежде всего Евразийский регион. В этой связи в части совершенствования международного сотрудничества в области предупреждения и ликвидации чрезвычайных ситуаций природного и техногенного характера и проведения аварийно-спасательных работ необходимо учитывать, что 29 мая 2014 г. был подписан Договор о Евразийском экономическом союзе (далее - Договор о ЕАЭС) главами Российской Федерации, Республики Беларусь и Республики Казахстан, который ратифицирован парламентами данных государств, и вступил в силу с 1 января 2015 г. Позже к Евразийскому экономическому союзу присоединились Армения и Кыргызская Республика. Таким образом, мы можем говорить о том, что созданный ЕАЭС открывает для государств новые возможности для эффективного международного сотрудничества в новом прогрессивном формате, а сама идея евразийской интеграции и евразийства точно соответствует всем общепризнанным принципам и нормам современного международного права [11].

Следует заметить, что Договор о ЕАЭС не касается вопроса о скоординированном реагировании государств-членов Евразийского экономического союза в части предупреждения и ликвидации чрезвычайных ситуаций природного и техногенного характера и проведении 
аварийно-спасательных работ. Однако риски, связанные с наступлением чрезвычайных ситуаций природного и техногенного характера, включая возможную тяжесть последствий от их наступления, неуклонно возрастают. В связи с этим для государств-членов Евразийского экономического союза, являющихся по отношению к друг другу сопредельными, дружественными и имеющими общие рынки, включая создание топливно-энергетического рынка, предусмотренного Договором о ЕАЭС, разработка и принятие международного договора о согласованных подходах государств-членов Евразийского экономического союза к предупреждению и ликвидации чрезвычайных ситуаций природного и техногенного характера и проведению аварийно-спасательных работ является весьма важной и актуальной задачей.

Таким образом, поскольку Договор о Евразийском экономическом союзе предполагает углубление регионального сотрудничества по целому ряду направлений, включая намеченное создание общего топливно-энергетического рынка, целесообразно предусмотреть под эгидой Евразийского экономического союза согласованный международно-правовой подход к предупреждению и ликвидации чрезвычайных ситуаций и проведению аварийно-спасательных работ.

Проект Договора о согласованных подходах государств-членов Евразийского экономического союза к предупреждению и ликвидации чрезвычайных ситуаций природного и техногенного характера и проведению аварийно-спасательных работ (далее - проект Договора) разработан инициативной группой специалистов Института законодательства и сравнительного правоведения при Правительстве Российской Федерации. Проект Договора призван регламентировать сотрудничество государств-членов в рамках Евразийского экономического союза в сфере предупреждения и ликвидации чрезвычайных ситуаций природного и техногенного характера и проведения аварийно- спасательных работ.

В настоящее время на постсоветском пространстве рассматриваемые вопросы регулируются, главным образом, посредством двусторонних международных договоров о сотрудничестве в области предупреждения и ликвидации чрезвычайных ситуаций, а также на уровне Содружества Независимых Государств в соответствии с многосторонними международными договорами. Данные международные договоры не отличаются достаточной проработанностью и в значительной степени устарели, что не позволяет говорить о создании на их основе достаточной и эффективной международно-правовой базы в области предупреждения и ликвидации чрезвычайных ситуаций природного и техногенного характера.

В связи с тем, что под эгидой Евразийского экономического союза государства-участники достигли наиболее высокой степени интеграции, то предлагаемый проект Договора может включать в себя апробированные и доказавшие свою эффективность решения, используемые в практике международного сотрудничества в сфере предупреждения и ликвидации чрезвычайных ситуаций природного и техногенного характера и проведения аварийно-спасательных работ..

Проект Договора предполагается разработать на межправительственном уровне, как и большинство международных договоров Таможенного союза - межгосударственного объединения, правопреемником которого стал Евразийский экономический союз.

В случае принятия и вступления в силу положения Договора о согласованных 
подходах государств-членов Евразийского экономического союза к предупреждению и ликвидации чрезвычайных ситуаций природного и техногенного характера и проведению аварийно-спасательных работ будут обладать приоритетом применения по отношению к национальному законодательству, что предопределяется Венской конвенцией о праве международных договоров 1969 г., а также закреплено в ч. 4 ст.15 Конституции Российской Федерации. Кроме того, самоисполнимые положения предлагаемого международного договора могут применяться непосредственно, что, в частности, предусмотрено в законодательных актах, регламентирующих вопросы заключения, реализации и прекращения международных договоров Российской Федерации.

В проекте Договора о согласованных подходах государств-членов Евразийского экономического союза к предупреждению и ликвидации чрезвычайных ситуаций природного и техногенного характера и проведению аварийно-спасательных работ предусматриваются следующие положения:

- цель договора;

- принципы сотрудничества;

- понятийный аппарат;

- наименования компетентных органов и формы их сотрудничества;

- возможности сотрудничества правительственных и неправительственных организаций;

- информационное взаимодействие;

- направления сотрудничества в области предупреждения и ликвидации чрезвычайных ситуаций природного и техногенного характера и проведения аварийно-спасательных работ;

- запросы об оказании помощи;

- порядок осуществления различных видов контроля;
- порядок оказания помощи;

- разрешение спорных вопросов;

- порядок вступления в силу и внесения изменений.

Проект Договора определяет порядок участия и осуществление взаимодействия по предупреждению и ликвидации чрезвычайных ситуаций природного и техногенного характера и проведения аварийно-спасательных работ государств-членов ЕАЭС (статья 3).

Проект Договора в статье 4 предусматривает, что компетентные органы Сторон отвечают за руководство и координацию реализации рассматриваемого Договора.

Для организации взаимодействия по вопросам, связанным с выполнением положений рассматриваемого Договора, компетентные органы Сторон установят между собой прямые контакты.

Компетентные органы Сторон определяют пункты связи для оперативного обмена информацией в рамках рассматриваемого Договора и информируют о них друг друга по дипломатическим каналам.

Компетентные органы в соответствии с национальным законодательством и в пределах своей компетенции могут развивать сотрудничество в рамках рассматриваемого Договора.

Кроме того, проект Договора предусматривает конкретные действия Сторон в случае оказания помощи, а также порядок уведомления Сторон в случае наступления чрезвычайных ситуаций.

В то же время необходимо отметить, что возникновение чрезвычайных ситуаций может быть вызвано факторами, имеющими совершенно разное происхождение, что не может не отразиться на соответствующем правовом регулировании, включая международное право. Так, большой блок чрезвычайных ситуаций составляют последствия, вызванные различными 
природными катаклизмами, катастрофами (например, цунами, ураганы, землетрясения, извержения вулканов, наводнения и т.д.). Другая группа чрезвычайных ситуаций может быть связана с техногенными катастрофами, последствиями взрывов электростанций, АЭС, ГЭС, пожарами, эпидемиями, которые вызваны антропогенными факторами (в том числе, помимо природных аномалий), но относятся к рискам, имеющим место в мирное время. Совсем другую группу рисков возникновения чрезвычайных ситуаций, составляют факторы, имеющие место в военное время. При этом, на наш взгляд, такие риски могут иметь место как при наличии вооруженных конфликтов международного, так и немеждународного характера.

К сожалению, в настоящее время отсутствует специальное международно-правовое закрепление согласованных подходов государств к реагированию при возникно- вении чрезвычайных ситуаций в условиях вооруженных конфликтов. Однако, по нашему мнению, ввиду острой значимости данного вопроса для международной безопасности выработка согласованных подходов государств к реагированию на чрезвычайные ситуации, имеющие последствия трансграничного характера, при наличии вооруженных конфликтов в одном или нескольких государствах, представляется весьма актуальной задачей. Данный вопрос тем более важен для государств, поскольку реагирование на трансграничные чрезвычайные ситуации в период вооруженных конфликтов и в мирное время может напрямую касаться суверенитета государства, что тем не менее не должно допускать умаления государственного суверенитета и вмешательства во внутренние дела государства на основе, не совместимой с общепризнанными принципами и нормами международного права.

\section{Библиография:}

1. Тиунов О.И., Каширкина А.А., Морозов А.Н. Статус международных межведомственных договоров Российской Федерации // Журнал российского права. 2007. № 1. С. 115.

2. Бражников Ю.В. Правовые аспекты международной гуманитарной деятельности России // Юрист-международник. 2004. № 4.

3. Второй доклад о защите людей в случае бедствий // http://www.unhcr.org/cgibin/texis/vtx/ refworld/rwmain/opendocpdf.pdf?reldoc=y\&amp;docid=4a5aefda2

4. Большов Л.А. Опыт Чернобыля и Фукусимы в предотвращении и ликвидации тяжелых радиационных аварий. В сб. Опыт ликвидации крупномасштабных чрезвычайных ситуаций в России и за рубежом. Материалы XIX Международной научно-практической конференции по проблемам защиты населения и территорий от чрезвычайных ситуаций. 20-23 мая 2014 г., Москва. 2014. С. 33.

5. Каширкина А.А. Международно-правовое сотрудничество государств в борьбе с экстремизмом // Журнал российского права. 2007. № 12. С. 75.

6. Данилова Е.Г. Совершенствование системы управления комплексной безопасностью и взаимодействие спасательных служб при ликвидации межгосударственных чрезвычайных ситуаций природного и техногенного характера. В сб. Опыт ликвидации крупномасштабных чрезвычайных ситуаций в России и за рубежом. Материалы XIX Международной научно-практической конференции по проблемам защиты населения и территорий от чрезвычайных ситуаций. 20-23 мая 2014 г., Москва. 2014. С. 488.

7. Каширкина А.А. Новые форматы в международно-правовом регулировании предупреждения и ликвидации катастроф и стихийных бедствий. В сб. Глобальная и национальные стратегии управления рисками катастроф и стихийных бедствий. XX Международная научно-практиче- 
ская конференция по проблемам защиты населения и территорий от чрезвычайных ситуаций. 19-21 мая 2015 г. М. С. 90-92.

8. См. официальный сайт Министерства Российской Федерации по делам гражданской обороны, чрезвычайным ситуациям и ликвидации последствий стихийных бедствий http://www.mchs. gov.ru/activities/international

9. Перечень международных договоров Российской Федерации межведомственного характера в рассматриваемой сфере, заключенных от имени МЧС России см. на официальном сайте Министерства Российской Федерации по делам гражданской обороны, чрезвычайным ситуациям и ликвидации последствий стихийных бедствий http://www.mchs.gov.ru/activities/ international/Soglashenija_mezhdu_MCHS_Rossii_i_zarube

10. Лафитский В.И., Каширкина А.А., Морозов А.Н. Проект Конвенции Организации Объединенных Наций по предупреждению и ликвидации последствий техногенных и природных катастроф // Журнал зарубежного законодательства и сравнительного правоведения. 2014. № 5. C. 876-883.

11. Каширкина А.А., Морозов А.Н. Формации правового развития евразийской интеграции и их влияние на правовую систему Российской Федерации // Журнал российского права. 2014. № 8. С. $73-83$.

\section{References (transliterated):}

1. Tiunov O.I., Kashirkina A.A., Morozov A.N. Status mezhdunarodnyh mezhvedomstvennyh dogovorov Rossijskoj Federacii // Zhurnal rossijskogo prava. 2007. № 1. S. 115.

2. Brazhnikov Ju.V. Pravovye aspekty mezhdunarodnoj gumanitarnoj dejatel'nosti Rossii // Juristmezhdunarodnik. 2004. № 4.

3. Vtoroj doklad o zashhite ljudej v sluchae bedstvij// http://www.unhcr.org/cgibin/texis/vtx/refworld/ rwmain/opendocpdf.pdf?reldoc $=y \& a m p ;$ docid $=4 \mathrm{a} 5 \mathrm{aefda} 2$

4. Bol'shov L.A. Opyt Chernobylja i Fukusimy v predotvrashhenii i likvidacii tjazhelyh radiacionnyh avarij. V sb. Opyt likvidacii krupnomasshtabnyh chrezvychajnyh situacij v Rossii i za rubezhom. Materialy XIX Mezhdunarodnoj nauchno-prakticheskoj konferencii po problemam zashhity naselenija i territorij ot chrezvychajnyh situacij. 20-23 maja 2014 g., Moskva. 2014. S. 33.

5. Kashirkina A.A. Mezhdunarodno-pravovoe sotrudnichestvo gosudarstv v bor'be s jekstremizmom // Zhurnal rossijskogo prava. 2007. № 12. S. 75.

6. Danilova E.G. Sovershenstvovanie sistemy upravlenija kompleksnoj bezopasnost'ju i vzaimodejstvie spasatel'nyh sluzhb pri likvidacii mezhgosudarstvennyh chrezvychajnyh situacij prirodnogo i tehnogennogo haraktera. V sb. Opyt likvidacii krupnomasshtabnyh chrezvychajnyh situacij v Rossii i za rubezhom. Materialy XIX Mezhdunarodnoj nauchno-prakticheskoj konferencii po problemam zashhity naselenija i territorij ot chrezvychajnyh situacij. 20-23 maja 2014 g., Moskva. 2014. S. 488.

7. Kashirkina A.A. Novye formaty v mezhdunarodno-pravovom regulirovanii preduprezhdenija $\mathrm{i}$ likvidacii katastrof i stihijnyh bedstvij. V sb. Global'naja i nacional'nye strategii upravlenija riskami katastrof i stihijnyh bedstvij. XX Mezhdunarodnaja nauchno-prakticheskaja konferencija po problemam zashhity naselenija i territorij ot chrezvychajnyh situacij. 19-21 maja 2015 g. M. S. 90-92.

8. Sm. oficial'nyj sajt Ministerstva Rossijskoj Federacii po delam grazhdanskoj oborony, chrezvychajnym situacijam i likvidacii posledstvij stihijnyh bedstvij http://www.mchs.gov.ru/activities/ international

9. Perechen' mezhdunarodnyh dogovorov Rossijskoj Federacii mezhvedomstvennogo haraktera v rassmatrivaemoj sfere, zakljuchennyh ot imeni MChS Rossii sm. na oficial'nom sajte Ministerstva Rossijskoj Federacii po delam grazhdanskoj oborony, chrezvychajnym situacijam i likvidacii posledstvij stihijnyh bedstvij http://www.mchs.gov.ru/activities/international/ Soglashenija_mezhdu_MCHS_Rossii_i_zarube 
10. Lafitskij V.I., Kashirkina A.A., Morozov A.N. Proekt Konvencii Organizacii Ob\#edinennyh Nacij po preduprezhdeniju i likvidacii posledstvij tehnogennyh i prirodnyh katastrof // Zhurnal zarubezhnogo zakonodatel'stva i sravnitel'nogo pravovedenija. 2014. № 5. S. 876-883.

11. Kashirkina A.A., Morozov A.N. Formacii pravovogo razvitija evrazijskoj integracii i ih vlijanie na pravovuju sistemu Rossijskoj Federacii // Zhurnal rossijskogo prava. 2014. № 8. S. 73 - 83. 